\title{
Al-ion Battery Based on Semi-Solid Electrodes for Higher Specific Energy and Lower Cost
}

David Muñoz-Torrero, Jesús Palma, Rebeca Marcilla, Edgar Ventosa*

Electrochemical Processses Unit. IMDEA Energy, Parque Tecnológico de Móstoles,

Avda, Ramón de la Sagra 3, 28935 Móstoles, Madrid. Spain.

E-mail: edgar.ventosa@imdea.org 
Section 1. Areal capacity in Al-ion batteries: state of the art.

The areal capacities demonstrated in literature are summarized in Figure S1. One can see that there is room for lowering battery cost by achieving areal capacities higher than those values.

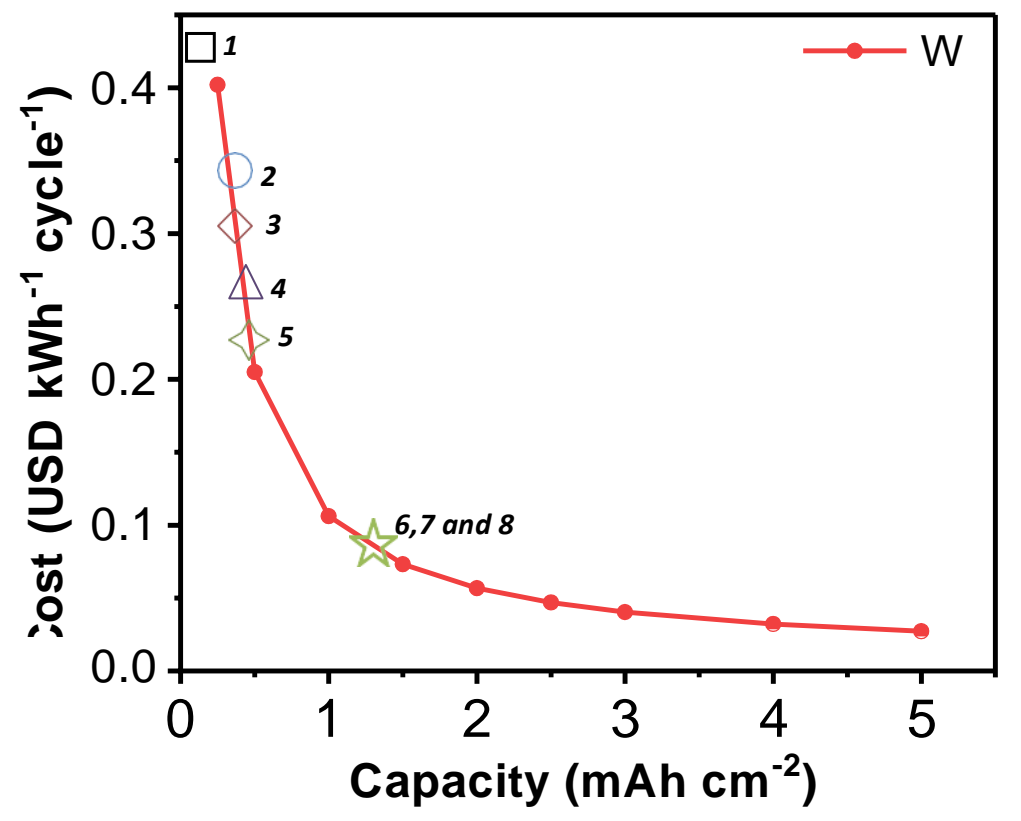

Figure S1. Energy cost vs Areal capacity using W as current collector. Energy cost for areal capacities reported in literature ${ }^{1-8}$.

Section 2. Experimental section 


\section{$\underline{2.1}$ Materials}

A commercial mixture of $\mathrm{AlCl}_{3}: \mathrm{EMImCl}(\leq 100$ iron $\mathrm{ppm})$ with a molar ratio of $1.5(r=1.5)$, synthetic graphite powder (SGP) and the binder (PTFE - $60 \mathrm{wt} \%$ dispersion in water)were purchased from Sigma-Aldrich. Synthetic graphite flakes (SGF) powder was obtained from IMERYS. And finally, Aluminiumn (Al) foil (99.9995\%) and Tungsten (W) foil (99.95\%) were purchased from Alfa Aesar.

\section{$\underline{2.2}$ Preparation of semi-solid cathode}

Semi-solid cathodes were prepared in an Ar-filled glovebox (Braun) with controlled water and oxygen content $\left(\mathrm{O}_{2}<1.2 \mathrm{ppm}\right.$ and $\left.\mathrm{H}_{2} \mathrm{O}<0.6 \mathrm{ppm}\right) .3 \mathrm{ml}$ of electrolyte was added to a syringe and immediately $1 \mathrm{~g}$ of graphite powder was incorporated. This mixture was stirred for a minute using a Pro Scientific Ultra-turrax Model PRO20. After that, $1 \mathrm{~g}$ of graphite (or the remaining amount) was again added to the mixture and then it was stirred again during a minute. This step will be repeated several times until the desired content of active material was reached. Table S1 shows the composition of the studied slurries. 
The electrode porosity was calculated as volume electrolyte / volume electrolyte + volume graphite, taking $2.2 \mathrm{~g} \mathrm{~cm}^{-2}$ as bulk density of graphite.

Table S1. Composition and porosity of the slurries used in this work.

\begin{tabular}{|c|c|c|c|c|}
\hline $\begin{array}{c}\text { Slurry } \\
\text { Mixture }\end{array}$ & $\begin{array}{c}\text { SPG content } \\
(\mathrm{g})\end{array}$ & $\begin{array}{c}\text { SPF content } \\
(\mathrm{g})\end{array}$ & $\begin{array}{c}\text { Electrolyte Volume } \\
(\mathrm{ml})\end{array}$ & $\begin{array}{c}\text { Electrode } \\
\text { Porosity (\%) }\end{array}$ \\
\hline 100SGP & 2.5 & 0 & 3 & 72 \\
\hline 95SGF:5SGP & 0.25 & 4.5 & 3 & 58 \\
\hline 100SGF & 0 & 5 & 3 & 57 \\
\hline M23 & 1.75 & 0 & 3 & 79 \\
\hline M20 & 2 & 0 & 3 & 77 \\
\hline M26 & 2.25 & 0 & 3 & 75 \\
\hline
\end{tabular}

\subsection{Electrochemical characterization of semi-solid cathode}

In order to study the electrical conductivity of semi-solid cathodes, electrochemical impedance spectroscopy (EIS) was used in two-electrode configuration (separator-free symmetrical cell) for each mixture. A schematic drawing of the set up can be found bellow,

Figure S2. The symmetrical cell consists of two Teflon plates that serve as package; two W foils, as blocking current collector, and one Viton joint with a rectangular cavity of 8 
$\mathrm{cm}^{2}$ and a thickness of $1 \mathrm{~mm}$. This space $(0.8 \mathrm{~mL})$ is filled with the semi-solid cathode.

And finally, the cell is closed with the help of a screws system.

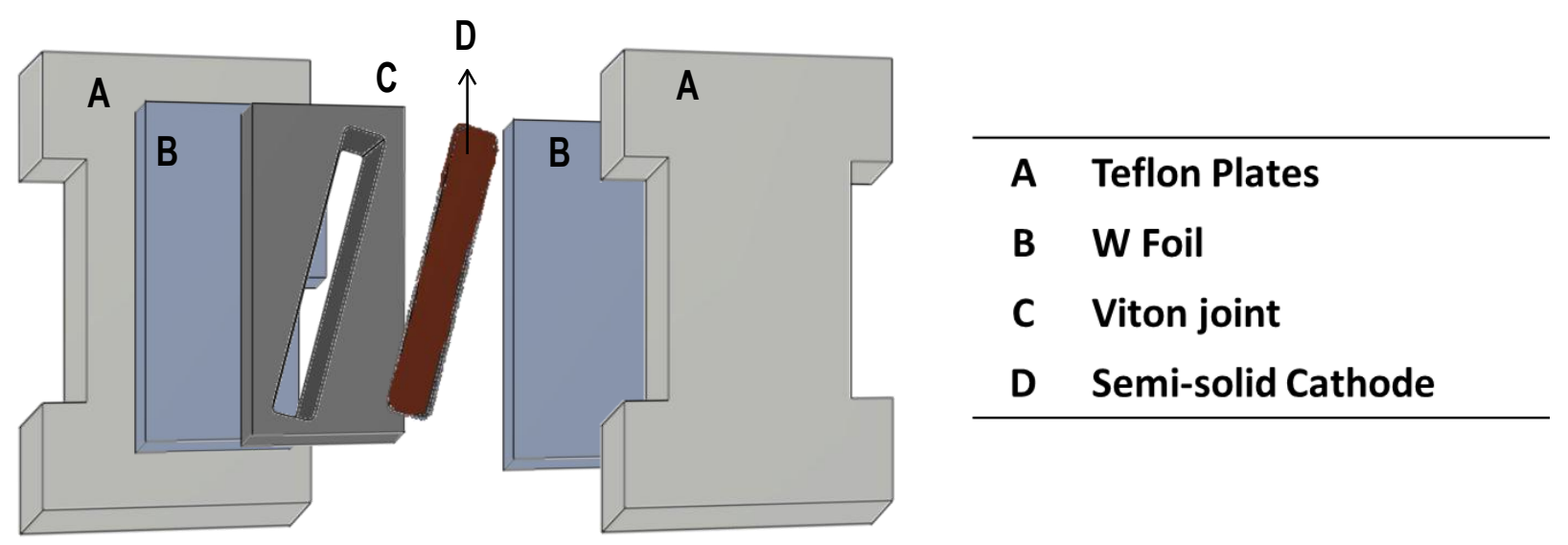

Figure S2. Symmetrical electrochemical cell designed for impedance of Semi-solid cathode.

\section{$\underline{2.4}$ Electrochemical characterization of Semi-solid Al-ion batteries.}

The semi-solid Al-ion batteries is constituted by two Teflon plates as package, the negative current collector was a mesh of $\mathrm{Al}$ onto an $\mathrm{Al}$ foil to ensure that the electrodeposition of $\mathrm{Al}$ occurs in a high surface area and, thus, the limited part of the battery is the positive side. A Whatman glassfiber soaked in electrolyte was used as separator. The semi-solid cathode was pasted onto the $\mathrm{W}$ positive current collector 
covering an area of $8 \mathrm{~cm}^{-2}$ and the volume was controlled by a gasket of Viton® of $1 \mathrm{~mm}$ of thickness. In order to study the influence of electrode thickness, cell assembled with 2 and $4 \mathrm{~mm}$ were assembled. To compare the performance of semi-solid batteries and conventional batteries, three cells were assembled using a solid cathode composed by graphite and PTFE in a proportion of 9:1 and with 1,2 and $4 \mathrm{~mm}$ thickness, respectively. Then the cells were closed using two Teflon plates fixed with screws.

\section{Section 3. Optimization of slurry.}

The optimization of the semi-solid slurry was carried out using the cell shown in Figure S2. For the optimization, two plates of $W$ were used as blocking electrodes while separator was not placed in between. In this configuration, one can evaluate the electrical conductivity of the slurries from electrochemical impedance spectroscopy (Figure S3a 
and S3b) using the equivalent circuit developed for mixed ionic and electric conductors (Figure S3c). For the semi-solid electrode of $72 \%$ electrode porosity, the electrical conductivity was in the order of $1.5 \mathrm{Ohm} \mathrm{cm}^{2}$ (for 2-mm thick electrode with 2 interfaces current collector - electrode).

a

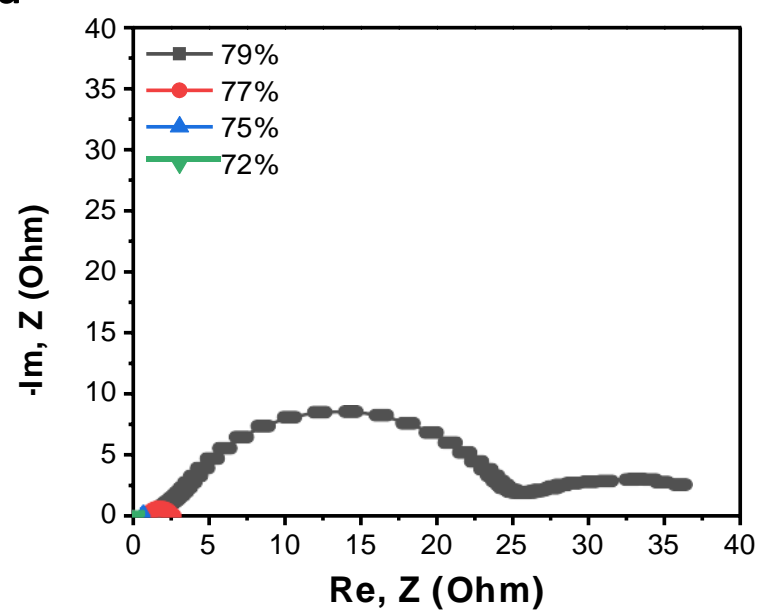

b

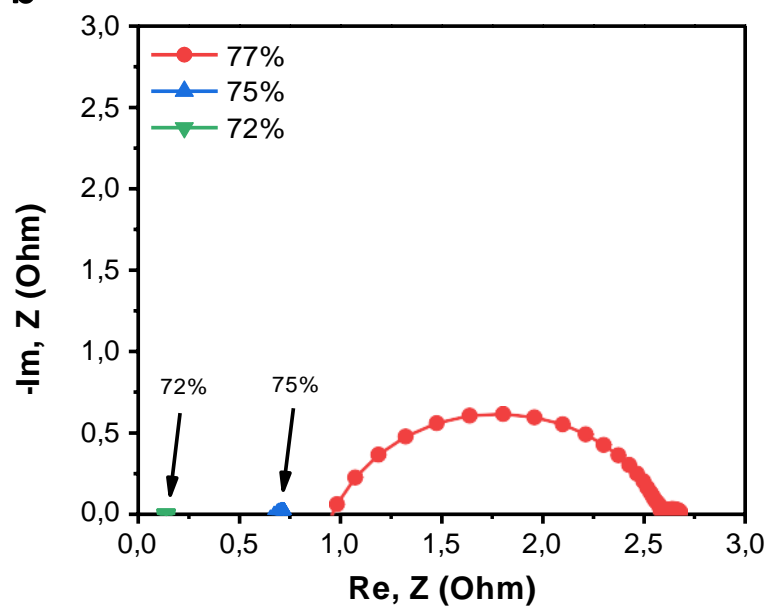

c

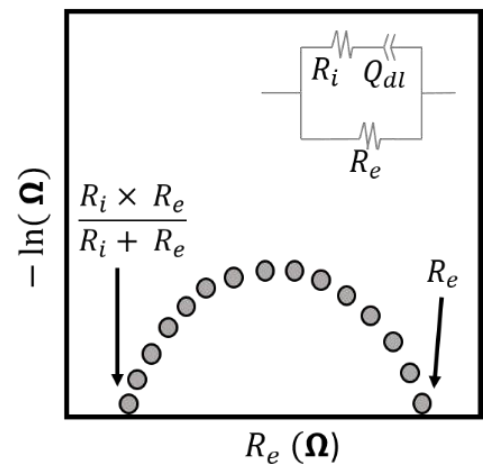

Figure S3. (a) Impedance spectroscopy for semi-solid mixtures with different porosities and (b) magnification of (a). (c) Illustration of the determination of the electrical conductivity from the EIS data using the equivalent circuit developed for mixed ionic and electric conductors. 


\section{Section 4. Negative electrode (anode) for high areal capacities.}

When demonstrating high areal capacities in Al-ion batteries, the negative electrode may become the limiting side. Figure S4 shows that the use of Al foil or Al mesh is not adequate for high areal capacities and it is necessary to combine Al foil and mesh to exceed 10 $\mathrm{mAh} \mathrm{cm}^{-2}$ to ensure that the positive electrode is the limiting one.

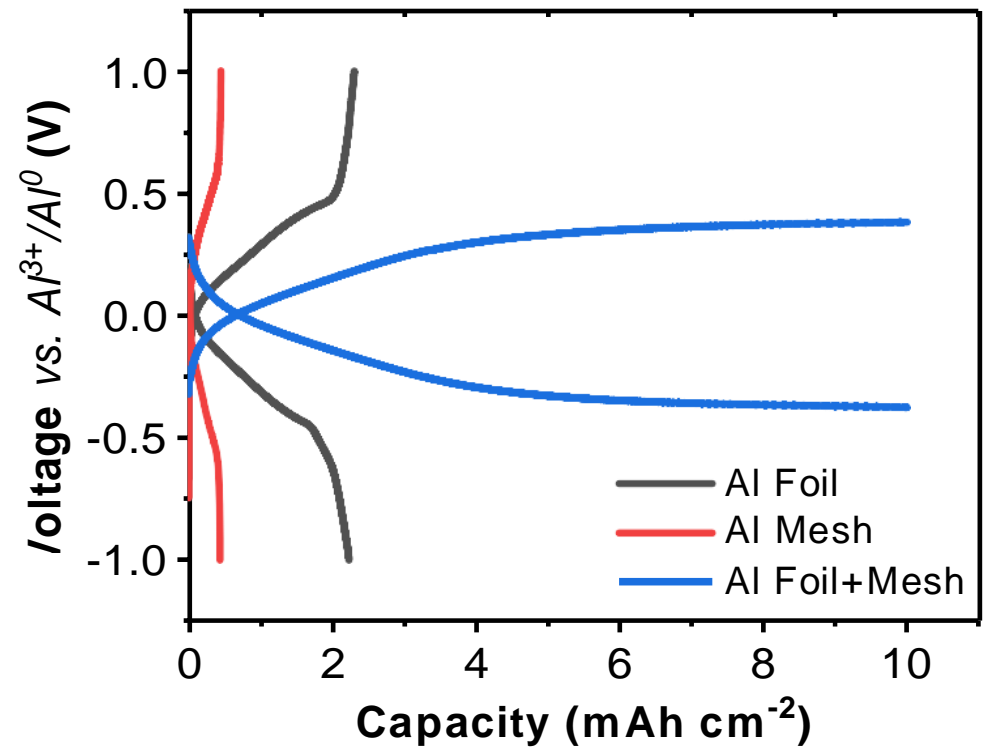

Figure S4. (a) Galvanostatic oxidation and reduction of Al in symmetric cell for Al foil (black) Al mesh (red) and Al Foil +Al mesh (blue).

Section 5. Utilization rate of active material 
Figures S5 and S6 show a comparison of specific capacities obtained when using conventional and semi-solid cathodes at different current densities.

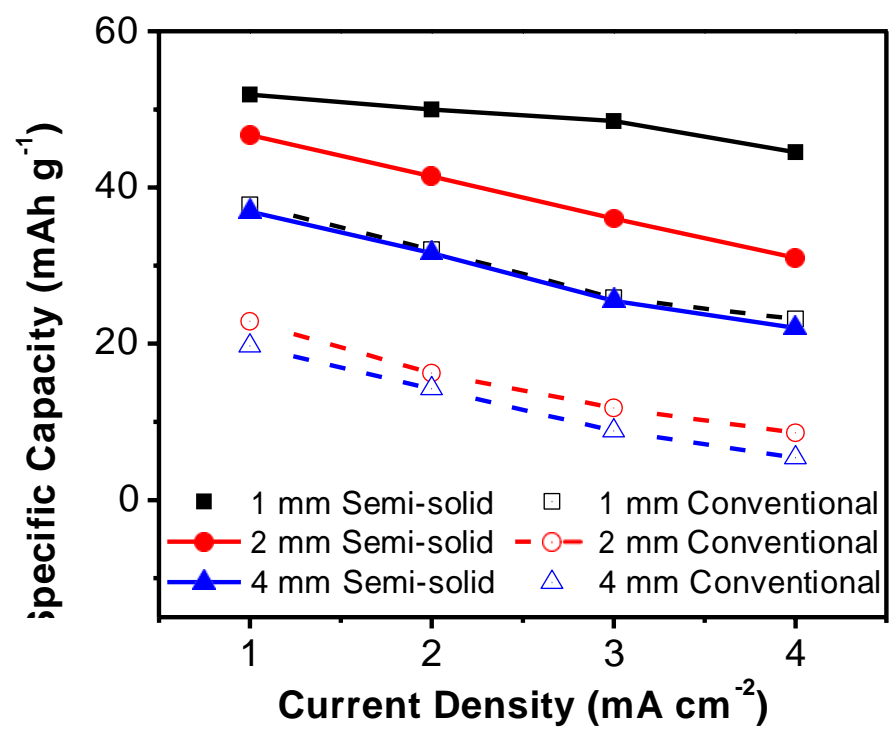

Figure S5. Specific capacity vs current density for conventional and semi-solid Al-ion Batteries with 1, 2 and $4 \mathrm{~mm}$ of thickness.

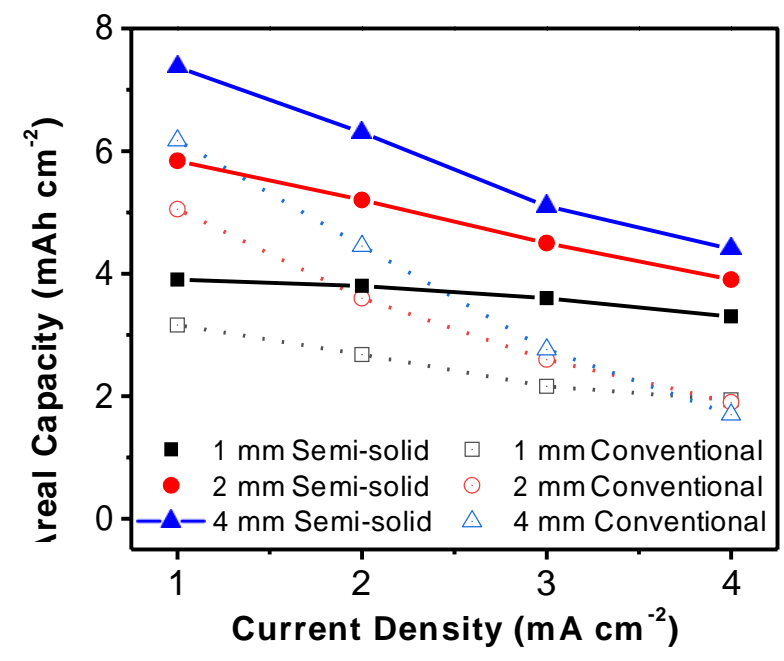


Figure S6. Areal capacity vs current density for conventional and semi-solid Al-ion Batteries with 1, 2 and $4 \mathrm{~mm}$ of thickness.

\section{Section 6. Estimation of ratio between effective diffusion coefficients.}

The diffusion coefficients of a conventional and of a semi-solid Al-ion battery were compared by means of electrochemical impedance spectroscopy (EIS). For that, batteries using conventional cathode and semi-solid cathode with a thickness of 4-mm were assembled to ensure mass transport limitation through the electrode. Both batteries were charged at $50 \%$ of the State of Charge and then, EIS measurements were conducted from $10 \mathrm{mHz}$ to $200 \mathrm{kHz}$ with an amplitude of $10 \mathrm{mV}$. In the low frequency region (Warburg region), the effective diffusion of the ions through the electrode can be obtained. The 
effective diffusion coefficient $(D)$ of the species can be calculated by following equations 9 :

$$
\begin{aligned}
& Z_{r}=R_{c t}+R_{S}+\sigma \omega^{-\frac{1}{2}} \\
& \mathrm{n}-\frac{22}{2 A^{2} n^{2} F^{4} C_{i}^{2} \sigma^{2}}
\end{aligned}
$$

As it can be seen in the equation (1), plotting $Z_{r}$ as function of the $\omega^{-\frac{1}{2}}$ a linear trend can be achieved. The slope of this line in low frequencies is the Warburg coefficient, $\sigma$, in $\Omega$ $\mathrm{s}^{-1 / 2}$. This value was calculated for batteries using a conventional cathode $\left(\sigma_{\text {conv }}\right)$ and a semi-solid cathode $\left(\sigma_{\text {semi }}\right)$.

Once the Warburg coefficient is calculated, the ratio between the two diffusion coefficient $\left(D_{\text {conv }}\right.$ and $\left.D_{\text {semi }}\right)$ can be obtainedsince the rest the parameters such as the gas constant $(R)$, the area $(A)$, the absolute temperature $(T)$, the number of electrons $(n)$, the Faraday constant $(\mathrm{F})$ and the concentration of the ions $\left(C_{i}\right)$ can be considered the same for both batteries. Therefore, the ratio between the diffusion coefficients is calculated as:

$$
\frac{D_{\text {semi }}}{D_{\text {conv }}}=\frac{\sigma_{\text {conv }}^{2}}{\sigma_{\text {semi }}^{2}}=\frac{0.9814^{2}}{0.7332^{2}}=1.79
$$




\section{Section 7. Molar ratio of the electrolyte}

Since the mass of the graphite was $1.09 \mathrm{~g}$ and the practical specific capacity of graphite was $51 \mathrm{mAh} \mathrm{g}^{-1}$, the total charge stored in the devices was $55.6 \mathrm{mAh}$

$\mathrm{C}_{\mathrm{g}}=1.09 \mathrm{~g}^{*} 51 \mathrm{mAh} \mathrm{g}^{-1}=55.6 \mathrm{mAh}$

Taking into account that the percentage of the electrolyte in weight was $46.4 \%$ and the mass of the graphite was $1 \mathrm{~g}$, the mass of the electrolyte was $=0.95 \mathrm{~g}$. Furthermore, $1 \mathrm{~mL}$ of electrolyte is added to the separator to soak it. The volume added was $\sim 1 \mathrm{~mL}$, which corresponded to $c a .1 .4 \mathrm{~g}$. Then, the total mass of the electrolyte was $2.35 \mathrm{~g}$. Based on the calculation developed by Kravchyk ${ }^{6}$, the capacity of the electrolyte for $r=1.5$ is $24 \mathrm{mAh}$ $\mathrm{g}^{-1}$. Therefore, the anode capacity was:

$\mathrm{C}_{\mathrm{a}}=2.35 \mathrm{~g} * 24 \mathrm{mAh} \mathrm{g}^{-1}=56.4 \mathrm{mAh}$

If lower amount of electrolyte is to be used in the separators, the higher molar ratio (1.5 2.0) will be required.

Section 8. Energy density and specific energy calculation 
The energy density and specific energy were calculating assuming a thickness for the $\mathrm{Al}$ and $\mathrm{W}$ current collectors of $50 \mu \mathrm{m}$ and a specific capacity of 80 and $50 \mathrm{mAh} \mathrm{g}^{-1}$ for conventional and semi-solid electrodes, respectively. An electrode porosity of 45 vol\% and 58 vol\% are used for conventional and semi-solid AlBs, respectively. It should be noted that $1 \mathrm{mAh} \mathrm{cm-2}$ is considered as state-of-the-art value for conventional AlBs while a value of $7 \mathrm{mAh} \mathrm{cm}^{-2}$ is demonstrated in this work.

\section{Section 9. Cost breakdown for conventional and semi-solid electrodes.}

The contributions of the battery components to the overall cost are given in Table S2.

First of all, it should be noted that the overall cost is reduced by $80 \%$. While the current collector is the main contributors to the cost for both conventional and semi-solid electrodes, the contribution of the electrolyte increases for semi-solid electrodes. Thus, the semi-solid based battery is expected to benefit from the significant advances in the production cost of ionic liquids. 
Table S2. Cost breakdown for a battery using conventional and semi-solid electrode

\begin{tabular}{|c|c|c|}
\hline Battery Component & $\begin{array}{c}\text { Cost (\%). Conventional } \\
\text { electrdoes. 1 } \mathbf{~ m ~ A ~ c m} \mathbf{~ c m}^{-2}\end{array}$ & $\begin{array}{c}\text { Cost (\%). Semi-solid } \\
\text { electrode. 7 m Ah cm }\end{array}$ \\
\hline Electrolyte & 14.2 & 26.9 \\
\hline Graphite & 3.8 & 18.1 \\
\hline Binder & 0.2 & 0 \\
\hline $\begin{array}{c}\text { Separator } \\
\text { Positive Current Collector } \\
\text { (W) }\end{array}$ & 6.7 & 4.5 \\
\hline $\begin{array}{c}\text { Al Foil (Negative Current } \\
\text { Collector) }\end{array}$ & 72.9 & 49.1 \\
\hline
\end{tabular}

\section{Section 10. References}

(1) Lin, M.-C.; Gong, M.; Lu, B.; Wu, Y.; Wang, D.-Y.; Guan, M.; Angell, M.; Chen, C.; Yang, J.; Hwang, B.-J.; Dai, H. An Ultrafast Rechargeable Aluminium-lon Battery. Nature 2015, 520(7547), 324-328. https://doi.org/10.1038/nature14340.

(2) Elia, G. A.; Ducros, J.-B.; Sotta, D.; Delhorbe, V.; Brun, A.; Marquardt, K.; Hahn, R. Polyacrylonitrile Separator for High-Performance Aluminum Batteries with Improved Interface Stability. ACS Appl. Mater. Interfaces 2017, 9 (44), 3838138389. https://doi.org/10.1021/acsami.7b09378.

(3) Wang, D.-Y.; Wei, C.-Y.; Lin, M.-C.; Pan, C.-J.; Chou, H.-L.; Chen, H.-A.; Gong, M.; Wu, Y.; Yuan, C.; Angell, M.; Hsieh,Y.-J.; Chen, Y.-J.; Wen, C.-Y.; Hwang, B.-Y.; Chen, C.-C.; Dai, H. Advanced Rechargeable Aluminium Ion Battery with a HighQuality Natural Graphite Cathode. Nat. Commun. 2017, 8, 14283.

(4) Pan, C.-J.; Yuan, C.; Zhu, G.; Zhang, Q.; Huang, C.-J.; Lin, M.-C.; Angell, M.; Hwang, B.-J.; Kaghazchi, P.; Dai, H. An Operando X-Ray Diffraction Study of 
Chloroaluminate Anion-Graphite Intercalation in Aluminum Batteries. Proc. Natl. Acad. Sci. 2018, 115 (22), 5670-5675. https://doi.org/10.1073/pnas.1803576115.

(5) Tsuda, T.; Uemura, Y.; Chen, C.-Y.; Hashimoto, Y.; Kokubo, I.; Sutani, K.; Muramatsu, K.; Kuwabata, S. Graphene-Coated Activated Carbon Fiber Cloth Positive Electrodes for Aluminum Rechargeable Batteries with a Chloroaluminate Room-Temperature Ionic Liquid. J. Electrochem. Soc. 2017, 164 (12), A2468A2473. https://doi.org/10.1149/2.0981712jes.

(6) Kravchyk, K. V; Wang, S.; Piveteau, L.; Kovalenko, M. V. Efficient Aluminum Chloride-Natural Graphite Battery. Chem. Mater. 2017, 29 (10), 4484-4492. https://doi.org/10.1021/acs.chemmater.7b01060.

(7) Wang, S.; Kravchyk, K. V.; Krumeich, F.; Kovalenko, M. V. Kish Graphite Flakes as a Cathode Material for an Aluminum Chloride-Graphite Battery. ACS Appl. Mater. Interfaces 2017, 9(34), 28478-28485. https://doi.org/10.1021/acsami.7b07499.

(8) Wang, S.; Kravchyk, K. V.; Filippin, A. N.; Müller, U.; Tiwari, A. N.; Buecheler, S.; Bodnarchuk, M. I.; Kovalenko, M. V. Aluminum Chloride-Graphite Batteries with Flexible Current Collectors Prepared from Earth-Abundant Elements. Adv. Sci. 2018, 5(4), 1-6. https://doi.org/10.1002/advs.201700712.

(9) Xiao, P.; Cai, Y.; Chen, X.; Sheng, Z.; Chang, C. Improved Electrochemical Performance of LiFe0.4Mn0.6PO4/C with Cr3+ Doping. RSC Adv. 2017, 7 (50), 31558-31566. https://doi.org/10.1039/c7ra04194b. 